\title{
关于苏联綜合机械化和自动化 的发展問題
}

\author{
И. И. 庫茲明 \\ （苏联部長会議副主席 苏联国家計划委界会主席）
}

我们国家目前正处值其产主义建設的新阶段。由

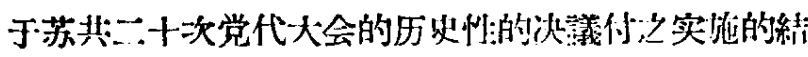
果, 在苏联的經济生活中引起了根本的变化。这种变 化使得社会主义工菲、农翡、运輸業以及其他国民經 济部"提高到环离的发眼阶段。

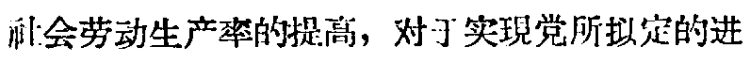

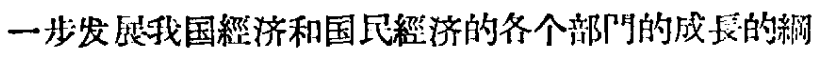
位，有着决定性:的意义。夘宁說过“資本主义可以被 彻底战胜, 而日一,一定会被彻底战胜, 因为社会主义能 造成新的高得多的劳动生产卒”。

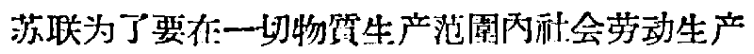

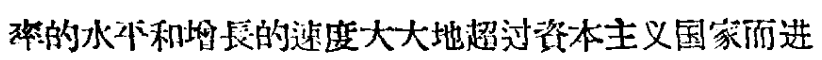
行的沵, 有着巨大的意义。这种外等是为完成苏联 主要的經济任务一为按人口不均分配的产品产量超 㳡先进的資本主义国家，为苏联經济实力的不断上浱， 为倠国內建立丰菑的物啠福利, 为逐步从祌:会主义过 渡到共产主义一而进行的外等中的一个有机部分。

在苏联, 与在社会主义陆营中的所有国家一样,

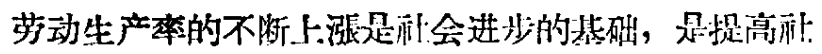
全一切成具的物饮福利和文化水次的背础。神会主义 陆营国策之阿的深入的社会主义劳动国际分工作很大 的程度上.更加快了这些国家劳动生产碎的发展速度。

在:战前, 俄国工籍生产來比总国低很多倍, 喵至 显著地低于英国和法国。目前, 苏联任劳动生产水水 方面已超过了英国和法国; 大大地繀短了苏联与美国 之嫍的距离。

苏联任劳动生产率的增長速度方面屌策第一 位。例如在我国的工紫战綫上，在同时繀短工作日的 情珿下，1957 年工人的作平均劳动生产率比 1913 年 增扣 8.5 倌。美国在这时候的劳动生产率仅仅增加了 1.3倍, 而法国与英国的劳动生产率则燳加得更少。

随着我国劳动生产卒的增㧈，在第一个五年計划 的年代里获得了整个工業产品增产 $51 \%$ 的成績, 作 籍二个五年計划內工業品增产 79\%，在战年的年代 和第四个五年計划期內工業品增产 $69 \%$ ，在第五个 五作詀划邓为 68 。根据苏联国家計划委貝会的維計，

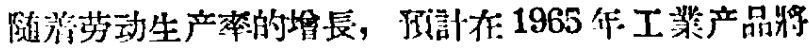
垉执 $80 \%$ 庄右。

苏联劳动生产率㙞長的飞快的速度，使资产阶极

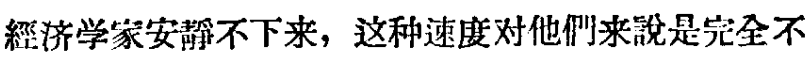
可想象的。某些資产㜾粐經济学家不惜提造事实, 以 便証实苏联劳动生产率高速度增辰是不可能的, 他們 硬說就是再过許多年, 美国的劳动生产率水可地仍然 將咅了苏联。

琽倫此亞大学教授华特・渡林生作他的漖作 “苏 联和美美国工業劳动生产著”中企图証明，从1939 作 起到 1950 年为止, 美国和苏联的劳动牛产率的均与长

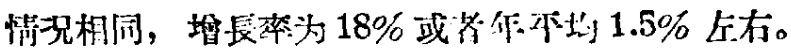
他假設今后美国劳动生产率逐年海辰不低于: $2 \%$ ，而

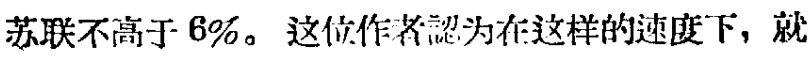
是在 1970 作, 苏联的劳动生产率也不会比美国荤动 生产率的 $80 \%$ 多忺多少。

但是現实生活証实了另一种情况，苏联从 1940 年起到 1950年，劳动生产䅗提高的不是 $18 \%$ 而足

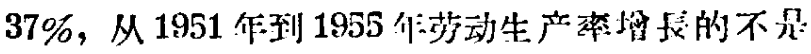

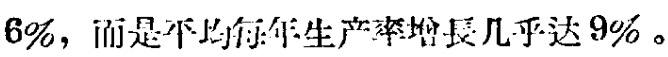

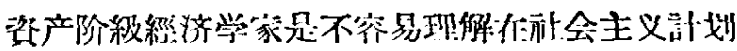

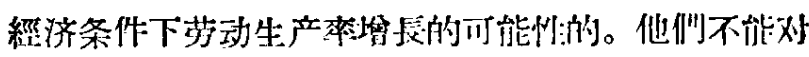

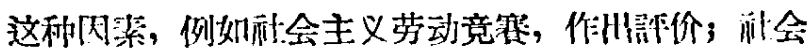
主义劳动竞赛的嘪正实管，对他們来訜是不可理解 的。资产阶級經济学家不能够话量在训会主义国家

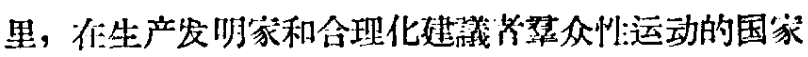
里, 技术改进因素的影响的价值。在这种国家》科学 为人民服务, 每个劳动者都知道, 劳动机械化和生产 过程自动化所引起的是劳动量的㺂船和劳动条件的改

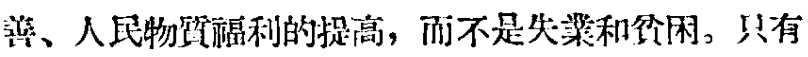
在資本主义的国家里, 劳动机械化和生产过程门动化 寸会引起失業和资困。

我們的国家現在已經面临这样一个发展阶段，在 这个阶段, 归于綜合机械化和广泛的自动化的实現, 由于生产条作和生产过程的改瓷, 劳动生产蓃將得到 从所米有的增長速度。建立新的形式的生产过程、作 
技术与生产組織中实施革命措施，劳动生产率的提高 就不是百分之几或盾百分之几十，而是若干倍。

网此，劳动生产率的显著提亳，是解次苏联基本

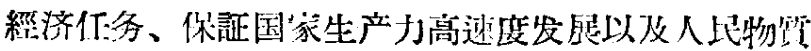
融利增段所必須的条件。

H. C. 赫奐嘵夫同志在二十次党代大会上說过： “苏联人上知道，提高劳动生产率是增进他们福利的 基础”。

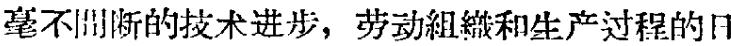
晙完语，生产过程紜合机械化和自动化的实施，是显 著地提高国民經济齐个部叮劳动生产率的基本条作。

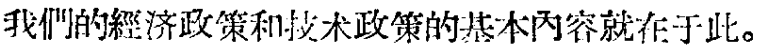

1957 年开尔斜矿 8420 万吨 (此 1913 作增州了 8 倍), 煤 46300 万吨 (此 1913 年增加了 15 倍)，不涪

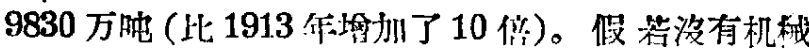
化的工作，要达到这种生产水不是不可能的。

保証生产的技术基地根本改变的工悲上、建設上 以及各国民經济部问中艰巨工程机械化程度的显著增 長，是我們很大的成就。但是我们不能停留有这一点 上.。列宁乍 1918 年就雷指示說: “全部閶题在习”不要 䩗足于我們以往的經驗中获得的本领，一定要领进， 一定要等取更多的东西，一定要从比較容星的仕务过 渡到比較网难的任务。否则就不可能有任何进步，也 不可能有形会主义建設中的进步。”

不能忘記，就是在那些主要生产过程机械化已經 达到很离程度的部門中，手工操作的数量还是十分多 的, 尤其是一些輔助的产生过程。这是由于远不是各 处都实現了繁重过程綜合机械化的緗故。这是机械化 事严的重要缺隐。

例如，在煤矿工筷中罙煤的主要过程号已机械化 了，而在回等掌子上陫积煤的机㭜化水不仅达 $37 \%$ 。 又如作那些主要工作过程不仪已經机械化了，而目岞 頗大程度上:已經自动化，投广泛地实行羙远距离自动 控制程序的火电站中，燃料践武的机械化程度至今仍 感不足。猉至在不久以前才投入运轉的契列彼斯国营

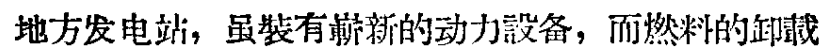
却不是机械化的。

在机械制造工業和金屬加工工篦中于工操作的面 分比也相当大。

我国晋通車林总数中，自动化和牛自动化其林的 此重还很不足。我們工厂所生产的車依，万能事应

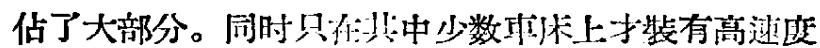

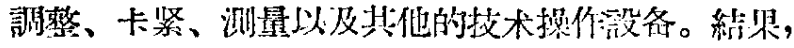

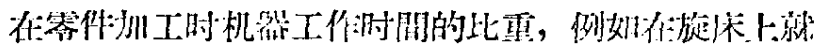
不大于 $40 \%$ 。

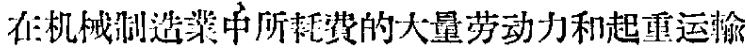

及堆放手續有关，和鉋厥的满理、調度工作、产品产 量的計算以及霓量的技术喻枝有关。运輸和堆放手稿 的机械化程度是漁差的, 运輸和堆放打續的劳动量本 均要佔制造机器总劳动量的 $25-30 \%$ 。们此, 在机

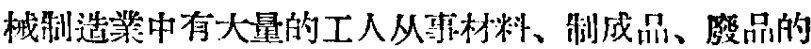
运輸工作和其他生产秦低的工作。

在荣些其他的工蓁部问方面也可以举出类似的例

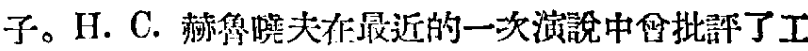
拝战綫上的工作人只，他們诘至連代替最筬單的但又 是艰下的乎工芳动的机器, 例如街通排冰器都沟有制 成。遗憾的是这不是个别现象。不論是在我們的方政

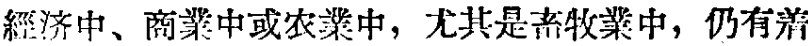
不少的手工工作。如果我們对机械化有了应有的更 形，我們就能节省很多劳力。

为了大大地减少手工工作，必須办速完成重劳动 过程的綜合机械化，排月.要大規模地进行現行殿备現 代化的工作。必须大大提高現代自动化車的产量和 机械化工具及测量裝置的生产，这利测量㱔置有机地 安裝有設备上仃来控制事休上.零件加工的精确度。

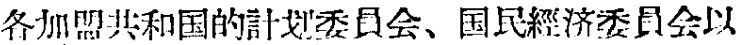

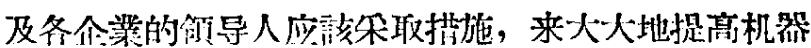
和机珹的产量, 其目的不仅在于使主要的生产过程机

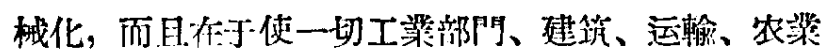
中的輔助过程和裝卸工作都机械化。

应該紧忍不拔地加快綜合机械化的实施，因为綜 合机械化为过渡到生产㳡程自动化和劳动生产㤝页大 的增長准备着条件。

如果招綜合机械化和自动化的概念之问树立葆一

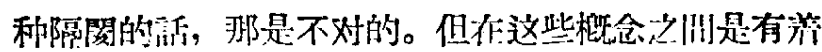

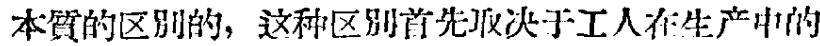
位置。如果綜合机械化使工人从再体力劳动中解技川

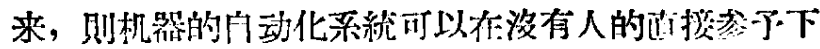
进行操作，人只是調整系紸和观筫系絖的操作。

向机器自动化系維过渡乃是我們的任务。

生产自动化是技术进步的总路䌊之一。不久以

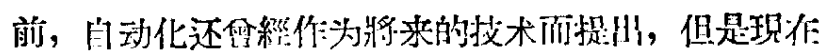
自动化已成了现代的捛术了。自动化起符生产縕䄉者 的偉大作伪, 它能够比較正确地引导生产过程的进行 和人大地維知产品生产的周期。间时降低耗电量，显 著地减少服务人的数量, 减少廢品和其他强失, 改 进产品筫量，降低产品成本，而更主要的是大大地提 高了劳动生产率。

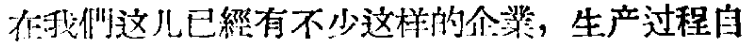

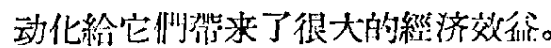

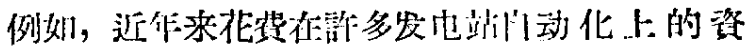

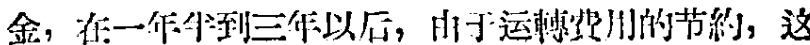




\section{些資金都已經收回来了。}

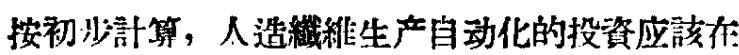
7-8个月队收回。松加伊斯工厂在人 造酒精提煉过 程自动化的情況下，产品产量增打了 2 倍，邦且能够使 一牛以上的工人有可能立做其他工作。頓湟茨苏打工 厂在碳酸化作用过程自动化的情况下，碳酸化塔的生

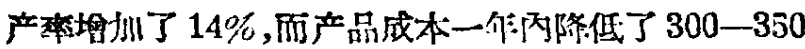
万虚狂。在叶弗列莫夫合成橡膠厂，歌多生产㳡程自

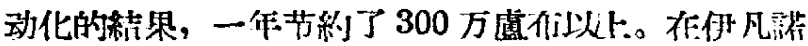
夫人造靴底公司，在生橡膠混合物制造車間和加工事 阔的流水作筷螕产生以原，生产周期的持續时間从 49 小时 40 分穛短到 1 小时 20 分，師 36 倍以上，而头 等产品产量从 $95 \%$ 提高到 $99 \%$ 。

計算証明，將 12 座高㠊自 动化的費用約为 600

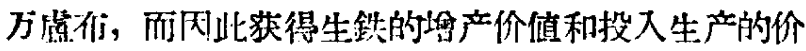
值 1 亿慮们的一座高嘘相等。

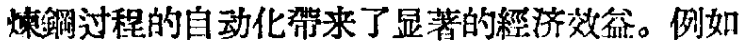
在馬格尼托高尔冶金公司，四个爐子綜合目动化的經 驗表明，仅仅作这个公司方面，由于苅动生产率的提

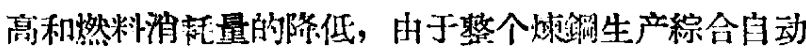
化的結果，银作节約 500 万等们以上。

在“紅色爱德䋍”工厂，共有 7 条生产金屬制品的 自动化綫在工作着，其总功率每年为 5,000 妕以上。 这些自动化綫是在标准設备的基础上裝备起来的。自 动化䋐的采用可以提高劳动生产率 3-4 倍, 降低金 䚄制品成本 40-50\%。

基輔工厂生产高氏鍊的自动化綫和莫斯科鏡表工 厂生产鐘表外壳零件的自动化綫的建立，可以提高劳 动生产率到 9-10 倍。

由于汽車工厂和拖拉机工厂建立．了自动化綫的結 果, 使劳动生产率提高了 1-3 悋。

在“紅十月”拖拉机备用零件厂，㧈工 354 型发动 机机头时，采用了兩条連鿓的自动化綫，絓果使調度 員的数量能够缄少 4.5 倍。发动机几头加工费用降低 了 $30 \%$ ，而重萌裝备流水作彗綫和花存自 动化上的 补充投资在 2 年左右就可以收回。

农業机械别造科学研究所建立的生产耙芷和鈎形 蹅的自动化綫是极有效谷的。用 8 条这样的自动化 總，每年可节約 2,000 万厉右虚布。

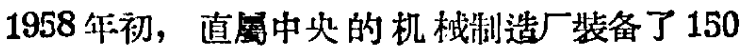

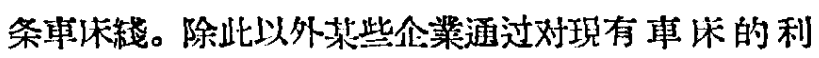
用, 自动裝备了約 200 条自动化車床綫，这些自动化

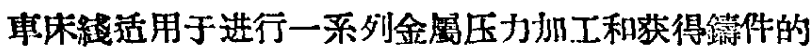
体制品了 几乎适用于一切机栈加工程序、質量檢查和 金屬的某些化学玒工程序。实际上在这些自动化綫上 检查了在机械制造中生产过程自动化存技术上的可能

\section{性和穏济一的合理性。}

根据苏联国芜計划委呈会的初步計算，在 1959

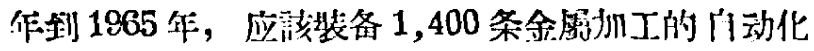

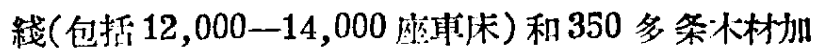

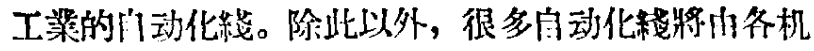
峨制造部”的工厂和設計局的自己力量来建立。

在电力系統中朵用自动化控制有着重大的意义。 存这里尔朋自动化控制, 不仅在于經济上的考虑, 而 首先是在于技术上的需要，因为若不广泛地尔用自动 控制和远距离自动控制, 则几我不可能管理电力系統 和系絹內各电站、变电站以及輸电綫的运行, 也不可 能保㻣国民經济的供电不受破坏。目前主要的电力系 統和大的变电站都是远距离操縱的。

近十年来知多火电站上都裴备了大量的热过程調 节的自动裝置，这促使了工作的可靠性和經济性的提 高，而且花費在自动調节装置上，的资金，用不到二：作。 的时間就可以收回。

現在冶金車問已开始朵用了高生产率的快速䡉

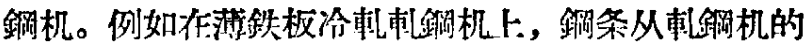
最后支架出来的速度可达 32 公尺/秒，印等于小海柬 的运动速度。用手操作这样的机休是不可能的。

在解决像掌握原子能和宇分渂样奥大的科学技术 問題时, 自动化的意义显得特别巨大。

仅仅由于有了現代自动化工具，才有可能来学提 砤多化学过程以及在高速度、高压和高溫下进行的各 种过程。

如果沒有完整的自动化操作过程，原于电站的建 立是不可想像的。將来在动力学中利用核了。应，山 仅仅在完整的自动化操作过程下才有可能。

对我們来說，自动化今天的意义也就类似当时作 我国实現了列宁的全俄电是化委呈会訃划时的电气化 的意义。目前，結合自动化、原子能以及无綫地电子 学为基础的技术革命紫已成熟。

采用电子訫算机来建立原則上是新的自动化系 統，为控制生产过程捉供了巨大的可能性:。

利肋檢驗工艺过程的仪器来作为傳感器, 则电子 計算机就能进行一切所需的計算手槕，扑且在各种参 数改变的惭况下，能够按照最理想的条件来独立操縱 工艺过程。用电子計算机可以使在生产条作下进行的 钎多計算手續完全自动化。

才綫电电子学已經更广泛地深入到苏联的国上緇 济中。4导体仪器的应用是有着特别重大的意义的。 因为牛导体仪器是制造电子計算机、电力整湉器、热 电发电机以及小尺寸的、經济的机峨的基础。

自动控制学是最年整的科学技术部間之一。但是 
我們已經为它在理論上的成就和技术应用上的成功而 感到自豪。例如，在苏联第一个建成了生产过程自动 化操作的独一无二的自动調整系統。在莫斯科殹維的 鉄路上完成了世架上第一次自动司机的試䮑，自动司 机 (沟有人的参与)按照已定的运行图使列方的调度! 有民好的指标, 这种指标比最有經驗的司机所达到的 还要好。制成了世界上第一部肘来确定不洞和天然气 产地最理想开尔方式的自动化机器, 尔用这衩机器的 經济价值达几亿觑们。在利利放射性同位素和光学声

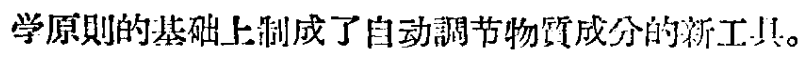

苏其二十次党代大会拟部了在治金工篦、不测工

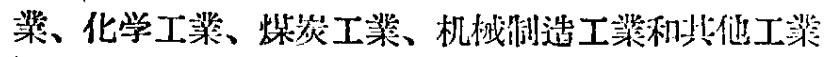
部阿中实施生产过程自动化的偉大綱领, 料目指川了 由个别机組和个别工序自动化过渡到型朐、生产过程 自动化以及整个企要自动化的必要性。

为了发展物質基础和保証生产过程自动化任务的 的完成, 决定大大地提高自动化仪器和工省、計算机 和計量分析机的生产, 扩大仪器制造的生产其础, 发 展仪器制造的科学研究和实驗基础, 扣强自动化快相 工作机器的层訃工作和生产工作, 以便解决与生产过 程自动操作佮关的复杂的数学唕題。

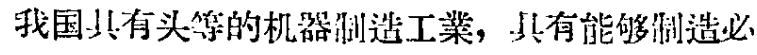
需的机器、工具、仪器的熟練的工作干部, 我仪有科 学研究所、实驗宗、設計局, 它們都拥有非常有經驗 的工程师和熟練的技术人兒，他们能够为一切工筑部

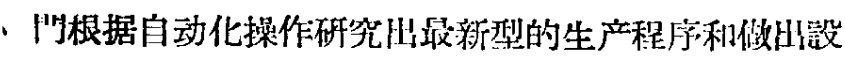
备所需的設訫。

H. C. 赫舅獍夫任苏联最高苏維埃紀仝会上指 H，“佂苏联的科学技术中，在茄联的工堂中，月解已 縉不你在我侧自己力量解决不了的生产技术間題”。

有了这和条件以后，我們就能够在生产日动化的

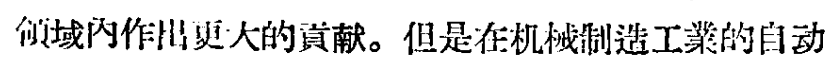
化綫上还只有少量車休在工作。在尔矿和洗紧企業中 生产过程自动化的程度还是不够的。初步部算証朋， 在一个煤岑工莱的洗煤工厂中，尔用他婀所坝分的白 动化方法和自动化工」的結果，能够解放五万人来做 品的工作。由于自动化，这些工厂的产量理以提高 1.5-2 倍左右。

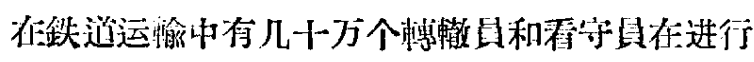
清投不复杂的、但却管常是繁重的工作，这些工作觉

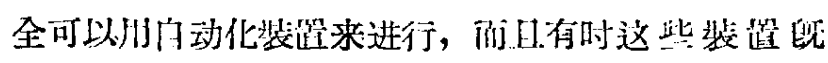

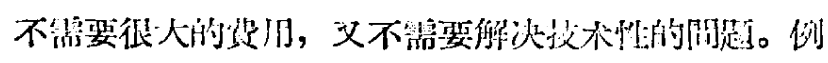

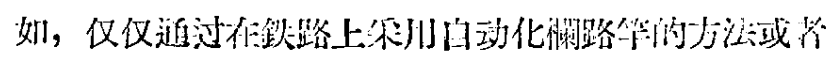

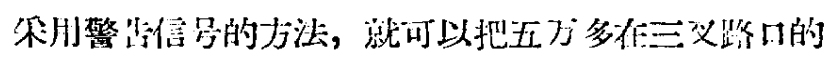
電等人解放情来。

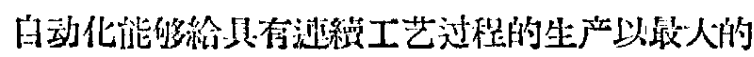

經济效夋。在这方面說起来, 化学工策便是为自动化

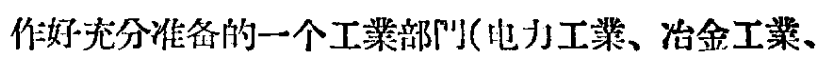

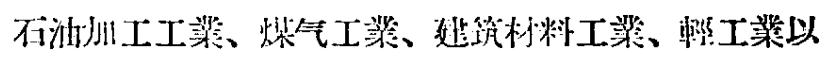
及位品工揱的装些部门(也是如此)。看起来, 正是化 学工等的生产过程, 应䠹已經在很大的規榄上目动化 了的, 但是, 作化学工筷中却仍然有大量工人从拈乎 工芳动。仅仅进行化学分析的人就有几千, 其实作应

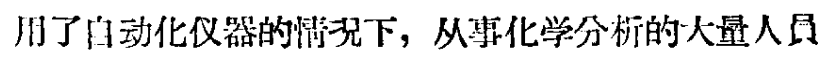
是可以解放忺来的。

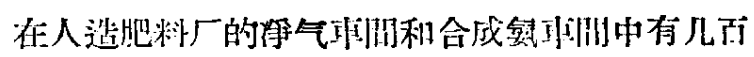

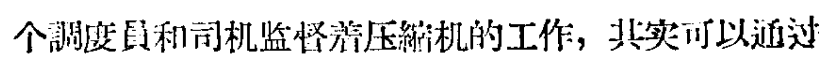

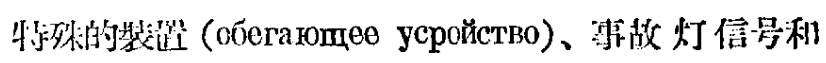

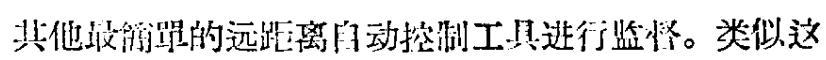

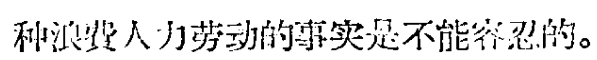

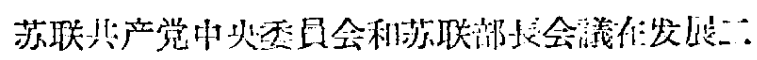

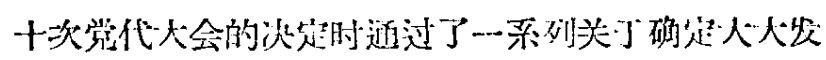

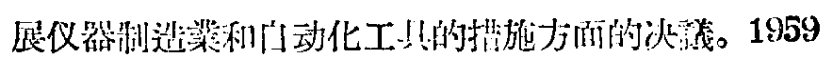

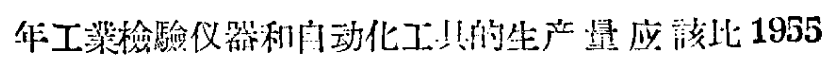

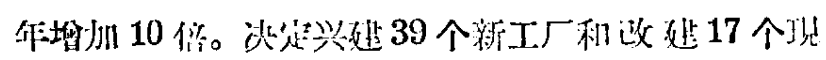
有工厂，但是这些任务光成得还不能 合人激意。作

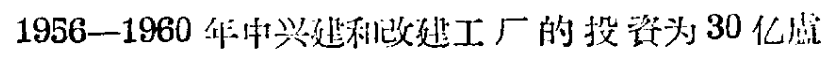
行，而 1956-1957 作仅江了其中的20\% 搦。

目前有些国上經济委员会对仪器工厂的兴建还济

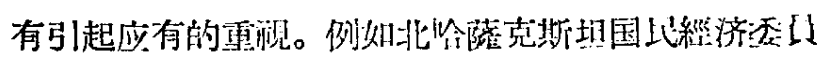
会在 1957 年需隆低了柯克然丹夫仪器工厂的投资和 彼得洛巴甫洛夫工厂的运用机栰設备数量; 絬果关与 这些建設的 1957 年的年度計划只光成了 $36 \%$, 而1958 年第一季度的計划仅完成了 $4 \%$ 。

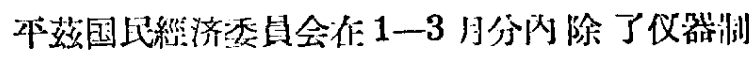
造厂以外, 完成了所有工萎部分的投得和建谓安裝工 作的計划。

馬里国民程济委員会几乎停止了仅器附作工厂的

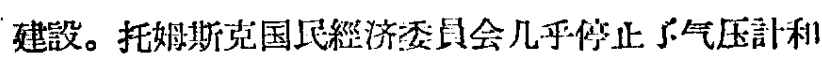
計算机工厂的兴建。这些为国民經济委员会的工作人

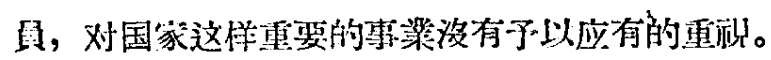

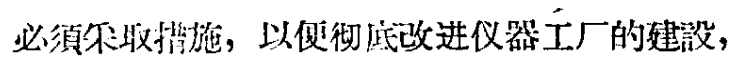

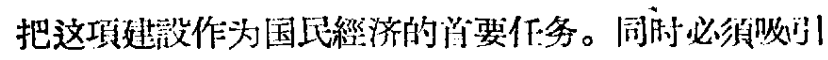

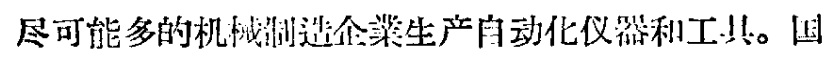

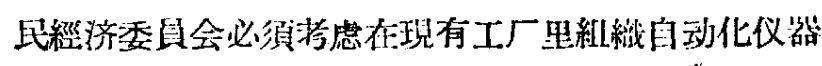
和工!!生产的阔題。

现代化的生产程序要求作为话报来源的仪器自动

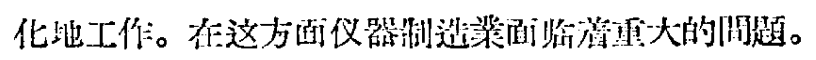

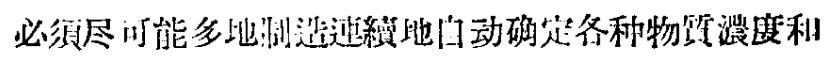

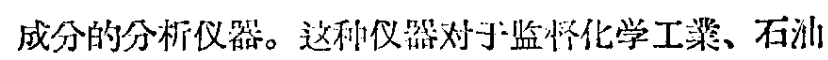
加工工業和其他工获部帅中的生产程序来說是极步重

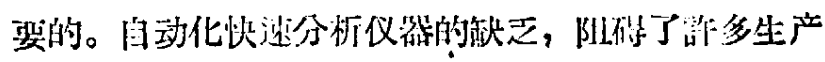


的綡合自动化。

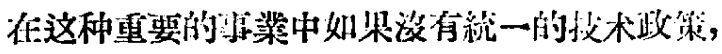

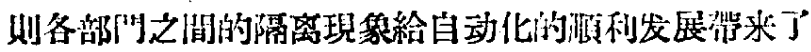
不少害处。每一个主管部门，每一个工業部句，䂙延

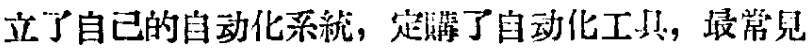
的是用自己力量研究出了和生产了独一无二的自动化 工具, 然而有时这种自动化工具的效率是比较小的,

自流性和分散性妨碍㫮設䚺标准化的实現和仪 器的統一，妨碍了各种自动化工具的規格化和 标准 化。因此，目前尔用先进的机組調节采統是有成难 的, 因为直接測量生产程序参数的仪器发出的勏号是 不統一的。正由于这个原因, 使得那种特殊裴谓 (обегающев устропство)的应用变得困难了, 虽然永: 一个这种設备都可以代替几百种部录仪器或省讀数仪 器, 未且可以减小控"制閵和自动裝置的尺寸达几十 倍。由于原始仪器的不統一, 阻碍了这样完善的自动 化工具 (例如控制計算机) 的利用。

为了貄立更有效的綜合自动化系統, 需要特训注: 意保証系統每一个元件的紹对可筑性。質量低劣的仪 器和調节器会降低自动化思想的价值。

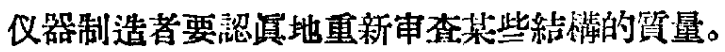
只有紹对可靠的元件才能堡定自动化仪器和工其的就 一的国家系統的基础。

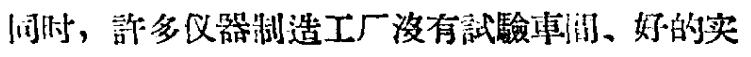

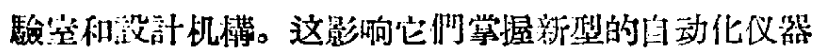
和技术工具, 拖長了新的自动化工具从开始研究到工 紫上旮分掌握的时间。

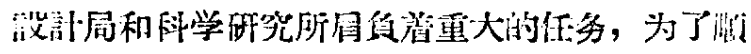
利比完成这些任务, 首先需要正确地淆备干部。任 是, 作没計人員不足时, 在桨些地方, 人员不合理使

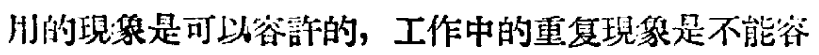

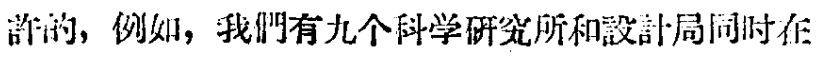
研究制造测量离毘子浱度用的同一种仪器。

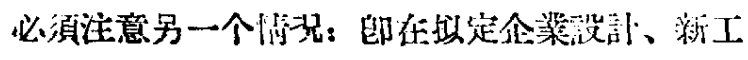

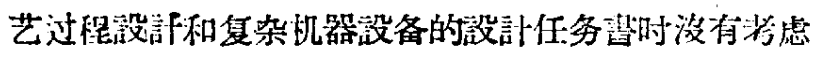
自动化閣題。这使最新技术难以推广, 这不仅使今天

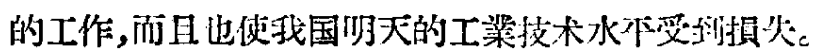

在自动化方面是彻統一的技术政策，不仅意味行

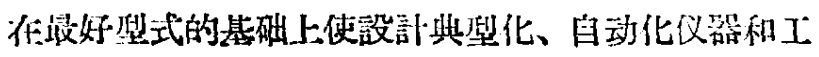

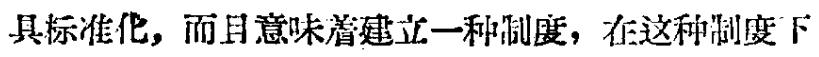

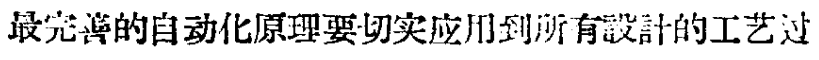

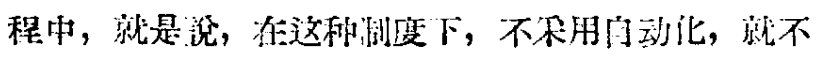
能完成机器和企檗的設計。

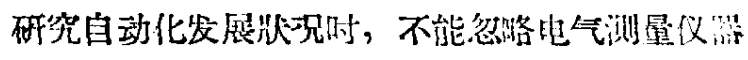
和电工没备的生产問題。沟有良好的电气测量仪器,

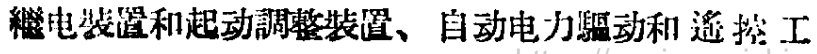

其, 不可能实現生产过程自动控洲。们以, 电工主

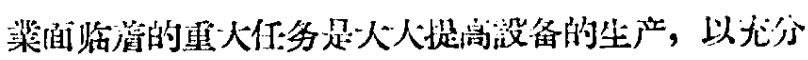
满足国民經济的需要。

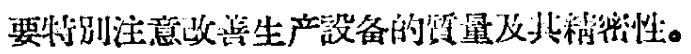

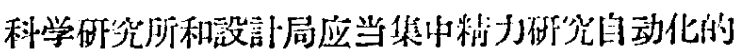

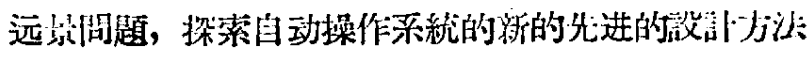

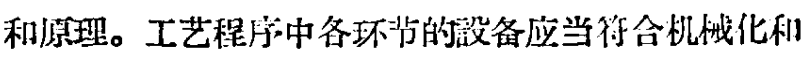

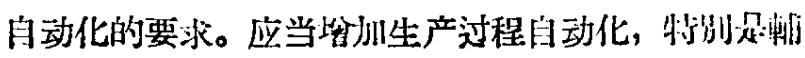
助工序自动化桎备的产量。

为了保証解㓅綜合机械化和自动化方面的们题，

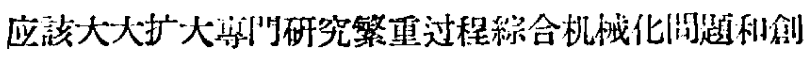

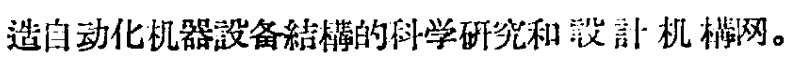

我国的机峨制造業生产了价值为 150 万狊价的压

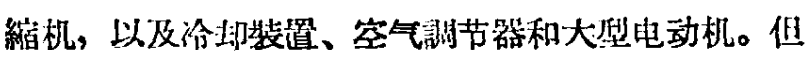
是, 其中大部分設备制造时洛有裝配适当的白动裴 证, 虽然这些自动裴置的价值較之信备本身的价值是 微不足道的。这种現像必須糺正。

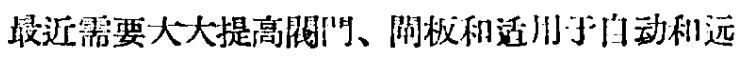

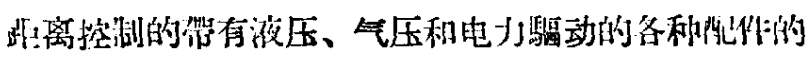

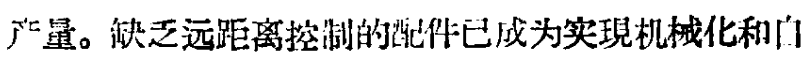
动化的障碍。」

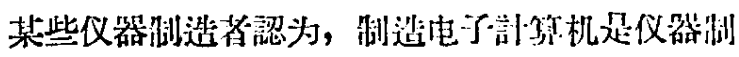

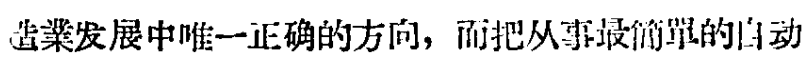
化工其的研究看成是不体面的哣访。

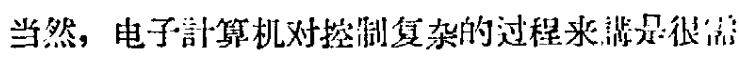

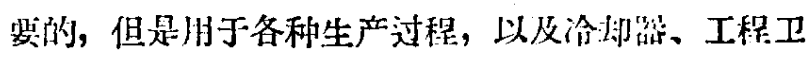

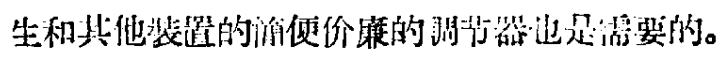

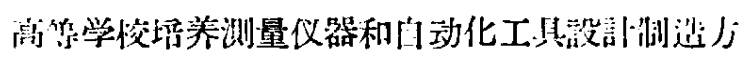

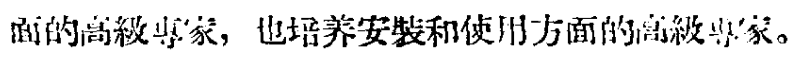

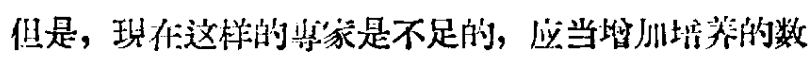

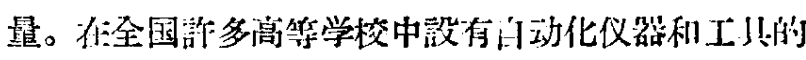

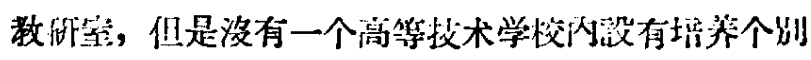
工業部恦生产自动化界家的系。

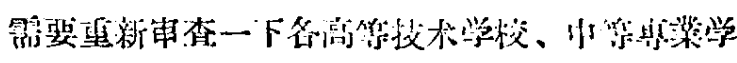

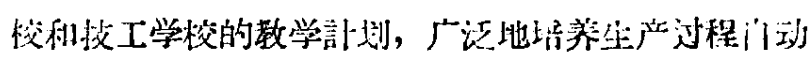

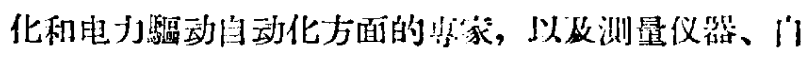

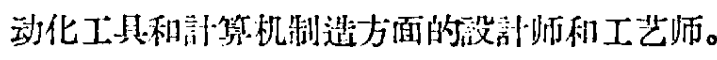

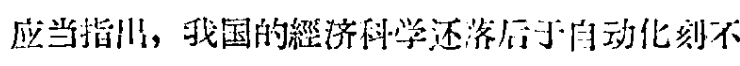

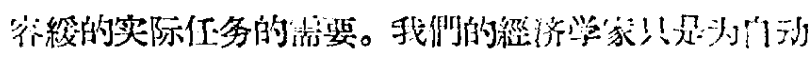

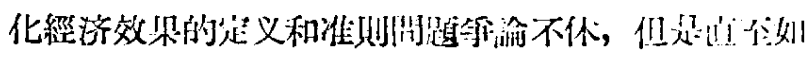

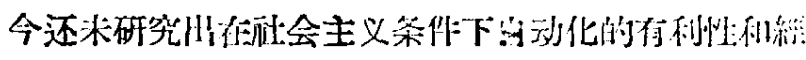
济效佰方面的理唃。

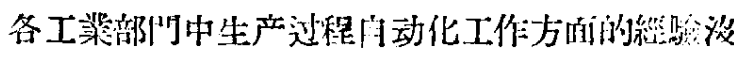

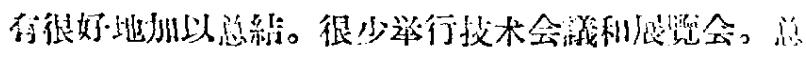

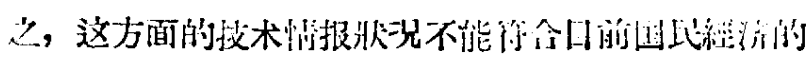
紫求。 


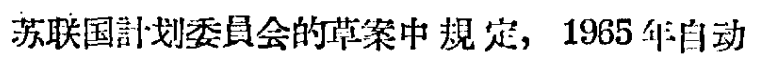

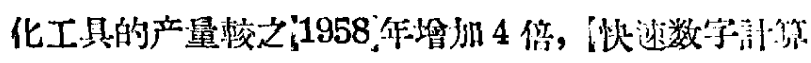

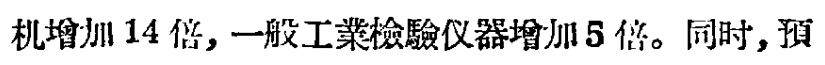
計制造 2000 多种新型 仪器和調节器。所有这一切, 要求大大加强仪器制造喿的生产和科学技术基地。

在这一事業中科学应当起很大作用。重要的科学 任务是研究控制計算机和自动控制的新原理, 这些計 算机的新原理要使自动化工程能够在其經驗积檍的过 程中自动改善, 粠能根据原料特性和其他因䇣的改变 自动調节。为了建立这种系統, 需要利用自动控例理 論全部的成就, 物理学、无綫电电子学、訃算技术和 其它許多学科的成就。只有这样, 㨢够建立各种过 程的精确和經济的控制系統，才能在各种不同的工業 部門中建立自动化工厂。

柇用新技术，可以使工程技术和計划經济計算、 現金山納和会計業务实現全面自动化，可以把人們从 效率不高的單調无味的劳动中解放帖来。使他們去从 事創造性的工作。为了实現这一点, 世需要广泛应䏚 控制計算机和訫算技术工其。

存制造自动化新的仪器和工具时, 特别要注意它

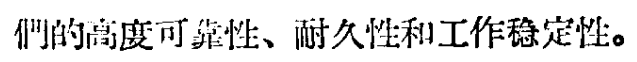

为了检驗个品高效率机器、机械裝嗢、白动化仪 唯和工具, 而更主要是为了檢驗生产各阶段的劳动机 栈化和过程自动化的机器系統, 最好在谷工業部鬥中

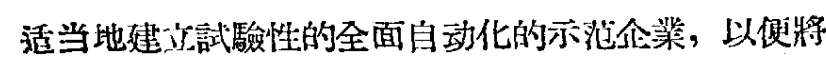
得到的䋑驗随后推广到其它的工厂中去。这种大梨的 和在各方面均可称为示汇的企等，肖先应当在治金部

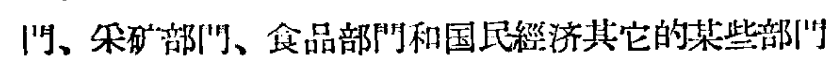
建汇起来。

上述自动化方面的任务, 应当在有科学技术和經 济低据的統一部划基础上来解决, 这个計划要在自动 化方法方面和工具方面都能体現川維一的抆术政策。

依落䕀一个机关或部”的力量是不能根本改善綜 合机峨化和自动化方面的工作的, 这製要国民經济各

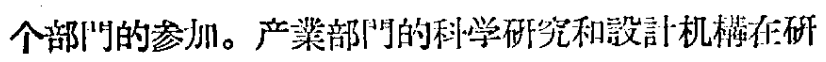

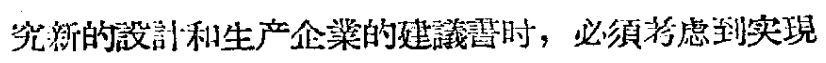
生产㳡程䋡合机械化和自动化的间题。在这方面, 国

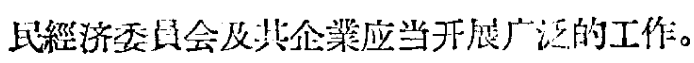

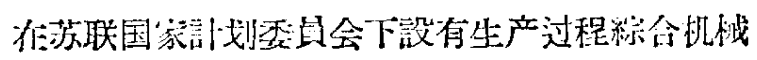
化和白动化们学技术委员会及自动化利。这样, 苏联

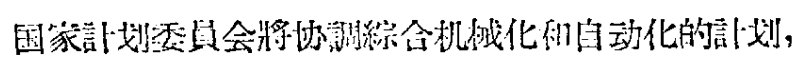
以及綜合机悈化、自动化工其和系統发展中的基本技 术方向, 监紧自恸化工作在的盟共和国中正确和及时 地进行。

在俄罗掀苏維诶联邦社会主义共和国建筑部的系
統率設有生产㳡程自动化总局, 其任务是保証自动化 各項綩合工作的完成, 包括設訃和綜合供应自动化需 要的仪器、調节器和器材, 最后保証各項安较調整工 作的完成，讲將㳂工的工程投入生产。在开始的时 侯, 这个总局不仅应該为俄罗斯联邦的需要服务, 而j 且还应該为其它扣㖞共和国的需要服务。

应当考虑, 在国民經济委員会內建主。具河的科 室，以便协調行政經济区域內所进行的自动化工作。

在实現統一的技术政策过程中, 呼究棕合机械化 和自动化問題的骨干科学研究所应該起很大的作用。 根据苏联共产党中央委員会和苏苏联部長会議的决 定, 在 1656-1657 年間建成了 14 个新的研究所和設 計局, 来研究自动化工具和自动控制系統。必需特別 注意和經常帮助这些研究所和設計局。以保証他們应 有的发展。

国民經济齐部|'的綜合机栈化和自动化不仅是发 展生产的头等重要的技术工具, 而且地是重要的政治 經济任务。

在苏联, 自动化和所有現代科学找术的成就一 样, 是大大损高劳动生产率、加速生产发展速店利例 造丰裕产品以改浐人民物筫生活的工具。

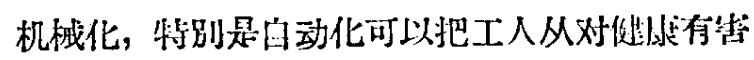

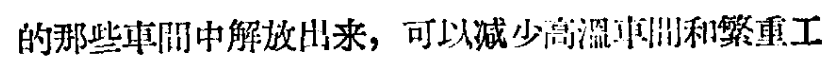
段的工人数量, 可以縮短工作川。在洏会主义条作F

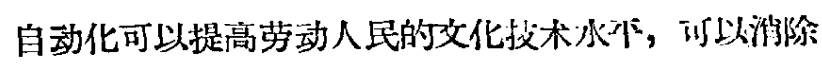
体力和腦力劳动之閏的差別。

在瓷本主义国家中完全是另外一种情洗。介藻主

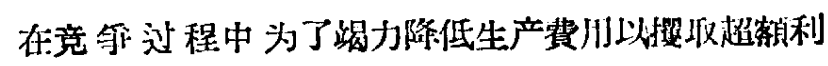
润, 不能不采用自动化。但是, 那里的白动化意味滋 大批㶧学者队伍的不断增加。

在新会主义条作下，任们人也不会想到生产机晠 化和自动化时他会失澲的問題。

因此, 从自动化的例子中，健可看到在不闰的社: 会經济条件下一一一方面是在苏联和沿着社会主义道 路前进的国家门，另一方面是在資本主义国家內一 技术发展的将点。

苏維埃人深信, 只有畒:会主义才能使科学技术为

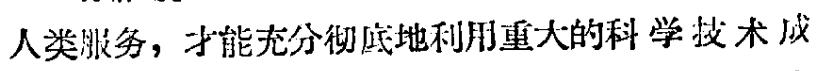
就，以造福人上零众。实現自动化必將无止境地提高 人类統治大自然的水柿。自动化是是技术进步和发级 我亚䣥会主义国家生产力的强大试器。

\section{[陈光耓于家珊 贈自 “苏眹科学院通报” 1958 年第 7 期了}

